\title{
Patients With IgA Nephropathy Have Altered Levels of Immunomodulatory C19 Steroids. Glucocorticoid Therapy With Addition of Adrenal Androgens May Be the Choice
}

\author{
I. ŠTERZL ${ }^{1}$, M. HILL ${ }^{1}$, L. STÁRKA ${ }^{1}$, M. VELÍKOVÁ ${ }^{1}$, R. KANČEVA ${ }^{1}$, J. JEMELKOVÁ ${ }^{2}$, \\ L. CZERNEKOVÁ ${ }^{2}$, P. KOSZTYU ${ }^{2}$, J. ZADRAŽIL ${ }^{2}$, K. MATOUŠOVIC ${ }^{3}, K^{\prime}$. VONDRÁK ${ }^{3}$, \\ M. RAŠKA ${ }^{2}$
}

${ }^{1}$ Institute of Endocrinology, Prague, Czech Republic, ${ }^{2}$ Palacky University and University Hospital Olomouc, Olomouc, Czech Republic, ${ }^{3}$ Second Faculty of Medicine, Charles University and Motol University Hospital, Prague, Czech Republic

Received July 11, 2017

Accepted July 16, 2017

\section{Summary}

Glucocorticoid (GC) therapy is one of the methods of choices for treatment of autoimmune diseases (ADs). In addition, adrenal androgens are known as immunoprotective GC-antagonists. Adrenal steroids preferentially influence the Th1-components over the Th2 ones. We investigated steroid metabolome (using gas chromatography-mass spectrometry) in healthy controls $(H)$, GC-untreated patients with ADs different from IgA nephropathy (U), GC-treated patients with ADs different from IgA nephropathy ( $\mathrm{T}$ ) and in patients with IgA nephropathy (IgAN), which were monitored on the beginning (N0), after one week (N1) and after one month (N2) of prednisolone therapy $(60 \mathrm{mg}$ of prednisolone $/ \mathrm{day} / \mathrm{m}^{2}$ of body surface). Between-group differences were assessed by one-way ANOVA, while the changes during the therapy were evaluated by repeated measures ANOVA. The ANOVA testing was followed by Duncan's multiple comparisons. IgAN patients and patients with other ADs exhibited lack of adrenal androgens due to attenuated activity of adrenal zona reticularis (ZR). Androgen levels including their 7a-, $7 \beta-$, and 16a-hydroxy-metabolites were further restrained by GC-therapy. Based on these results and data from the literature, we addressed the question, whether a combination of GCs with $\Delta^{5}$-steroids or their more stable synthetic derivatives may be optimal for the treatment of antibodies-mediated ADs.

\section{Key words}

Glucocorticoid therapy • Adrenal androgens • Immunomodulatory steroids • Gas chromatography-mass spectrometry • Steroid metabolome

\section{Corresponding author}

M. Hill, Institute of Endocrinology, Národní třída 8, 11694 Prague 1, Czech Republic. E-mail: mhill@endo.cz

\section{Introduction}

IgA nephropathy (IgAN) is the most frequent primary glomerulonephritis worldwide. In this autoimmune disease, aberrantly O-glycosylated IgA1 hinge region serves as an antigen recognized by antiglycan antibodies. This stimulates a formation of nephritogenic immune complexes (Mestecky et al. 2013), the accumulation of which in the kidney mesangium induces a proliferation of mesangial cells, expansion of extracellular matrix proteins and renal injury, leading to an end-stage renal failure in $20-40 \%$ of patients. Progressive IgAN patients may be treated with glucocorticoids (GCs) (Lai et al. 2016, Matousovic et al. 2015). However, this therapy in IgAN is questionable (Lv et al. 2012, Rauen et al. 2015, Tesar et al. 2015). Although GC-administration represents the most powerful therapy for rapid attenuation of inflammatory response, longtime GC-treatment is accompanied by serious complications such as disruption of hypothalamopituitary-adrenal (HPA) axis and inhibition of gonadal activity (Mastorakos et al. 2006, Rengarajan and Balasubramanian 2008). As adrenal androgens are GC-antagonists, we evaluated their levels in groups of healthy controls $(\mathrm{H})$, GC-untreated $(\mathrm{U})$ and GC-treated 
(T) patients with other autoimmune diseases (ADs), and in IgAN patients before prednisolone treatment (NO), and after one week (N1) and one month (N2) of prednisolone therapy. Since natural $7 \alpha / \beta$ - and $16 \alpha$-hydroxy-steroids are immunomodulatory, anti-inflammatory and immunoprotective (Ahlem et al. 2011a, Ahlem et al. 2011b, Auci et al. 2009, Conrad et al. 2010, Hennebert et al. 2007, Le Mee et al. 2008, Loria 2002, Pettersson et al. 2010, Reading et al. 2012, Tang et al. 2006) we focused on these substances.

\section{Methods}

\section{Subjects}

The study enrolled 23 women and 43 men. The study groups consisted of healthy controls $(H, n=10)$, untreated controls without IgAN but suffering from other ADs $(U, n=10), G C$ treated non-IgAN controls suffering from other ADs $(\mathrm{T}, \mathrm{n}=9)$, and patients with $\operatorname{IgAN}(\mathrm{n}=14)$ who were monitored before prednisolone treatment (N0), after one week (N1) and one month (N2) of prednisolone therapy. The U-group enrolled patients with idiopathic membranous glomerulonephritis, nephrotic syndrome, membranous glomerulonephritis, glomerulopathy, and suspenzia chronic mesangioproliferative glomerulonephritis. The T-group consisted of patients with rheumatoid arthritis, systemic lupus erythematosus, ankylosing spondylitis, systemic impairment of connective tissues, polymyalgia rheumatica and giant cell arteritis, membranous nephropathy, complete nephrotic syndrome and glomerular and segmental glomerulosclerosis. Prednisolone dose was $60 \mathrm{mg}$ of prednisolone $/ \mathrm{day} / \mathrm{m}^{2}$ of body surface. The patients have been recruited from the Nephrological Outpatient Department (NOPD) of the Motol University Hospital and from the neighboring NOPDs in Prague and NOPD of Palacký University Olomouc. No samples from the female subjects were collected in the luteal menstrual phase. The mean age of the participants was $48.4 \pm$ 15.1 years $($ mean $\pm \mathrm{SD})$ and the age differences between the study groups were insignificant.

The Ethics Committee of the Institute of Endocrinology in Prague approved the protocol of the study, and written informed consent was obtained from all participants.

\section{Analytical methods}

The circulating levels of steroids and their polar conjugates were measured using a previously described gas chromatographic-mass spectrometric method (Hill et al. 2010).

\section{Statistical analysis}

The between-group differences were evaluated using one-way ANOVA. Changes in steroid levels were assessed using repeated measures ANOVA. The ANOVA testing was followed by Duncan's multiple comparisons (Duncan 1955). The original data were transformed by power transformations to attain Gaussian data distribution and constant variance. Statgraphics Centurion, version XV statistical software from Manugistics, (Herndon, MA, USA) was used for the calculations.

\section{Results}

\section{Steroid levels}

Most steroids showed significant between-group differences (Table 1) and there was a trend of decreasing in steroid levels during the prednisolone therapy (Table 2). Estradiol was higher in the IgAN patients irrespectively of GC-treatment.

Shifted balance between adrenal C21 and C19-4 $\Delta^{5}$ steroids towards the C21 steroids in IgAN patients

Dehydroepiandrosterone (DHEA) to pregnenolone ratio (Fig. 1A) was higher in the H-group than in the other groups while the dehydroepiandrosterone sulfate (DHEAS) to pregnenolone sulfate ratio did not significantly differ between the $\mathrm{H}$ and N0-groups (Fig. 1B). Both ratios (reflecting CYP17A1 lyase step) decreased during the GC-treatment of IgAN patients. The values and statistics for repeated measures ANOVA in the DHEA/pregnenolone ratio were $\mathrm{F}=26.51$, $\mathrm{p}<0.001: \mathrm{N} 0=5.66 \quad(4.72,6.73$ - mean with $95 \%$ confidence limits), $\mathrm{N} 1=2.7(2.14,3.36), \mathrm{N} 2=2.06(1.57$, 2.64), N0-N1, N0-N2 (significant differences between stages N0 and N1 and between stages N0 and N2). For the DHEAS/pregnenolone sulfate ratio they were $\mathrm{F}=4.02$, $\mathrm{p}=0.031: \mathrm{N} 0=15.2 \quad(12.3,18.6), \mathrm{N} 1=11.9 \quad(9.69,14.5)$, $\mathrm{N} 2=10.1(8.22,12.4), \mathrm{N} 0-\mathrm{N} 2$.

Increased conversion of DHEA to androstenedione reflecting type 2 3B-hydroxysteroid dehydrogenase (HSD3B2) activity in IgAN patients

Androstenedione/DHEA (Fig. 1C) and androstenedione/DHEAS (Fig. 1D) ratios reflecting type 2 33-hydroxysteroid dehydrogenase (HSD3B2) activity were higher in the GC-treated groups. The values 

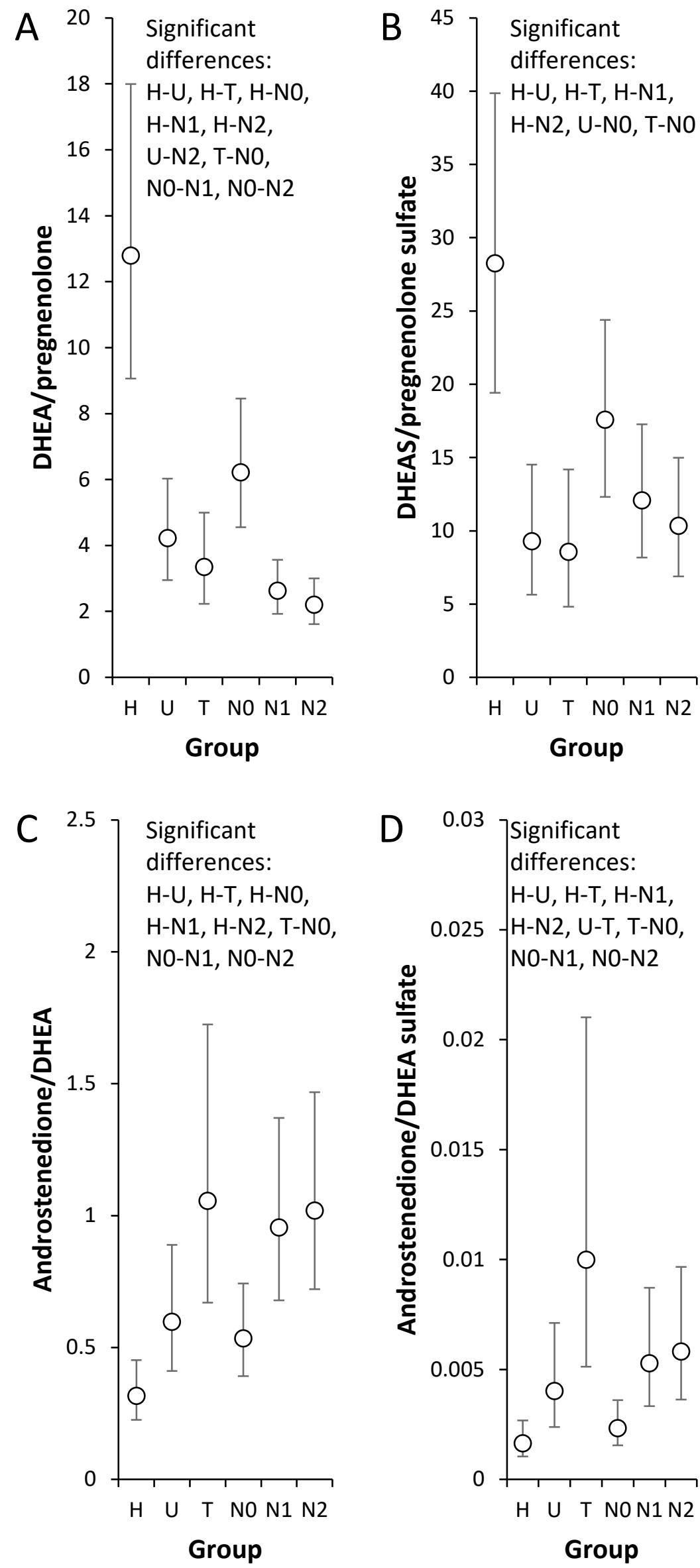

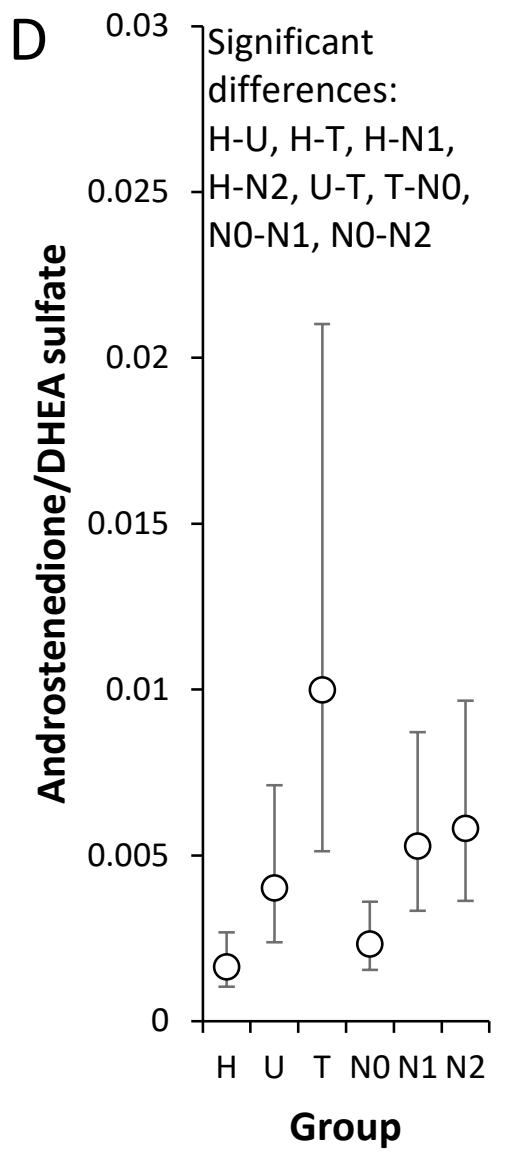

Fig. 1. Product to precursor ratios (PPRs) in groups of healthy controls $(H)$, glucocorticoiduntreated patients with autoimmune diseases (ADs) different from IgA nephropathy (IgAN) (U), GC-treated patients with non-IgAN ADs (T) and in IgAN patients on the beginning of prednisolone treatment (N0), after one week (N1) and after one month (N2) of the therapy. The circles with error bars represent re-transformed means with their $95 \%$ confidence intervals (for details see section Statistical analysis). The embedded tables show all significant between-group differences $(p<0.05)$ as evaluated by Duncan's multiple comparisons. The symbols separated by hyphen represent significant between-group differences $(p<0.05)$. Panels $\mathbf{A}$ and $\mathbf{B}$ show the PPRs reflecting a balance between adrenal C21 and C19- $\Delta^{5}$-steroids, while panels $\mathbf{C}$ and $\mathbf{D}$ show the PPRs reflecting the activity of type 2 17ß-hydroxysteroid dehydrogenase (HSD17B2). 


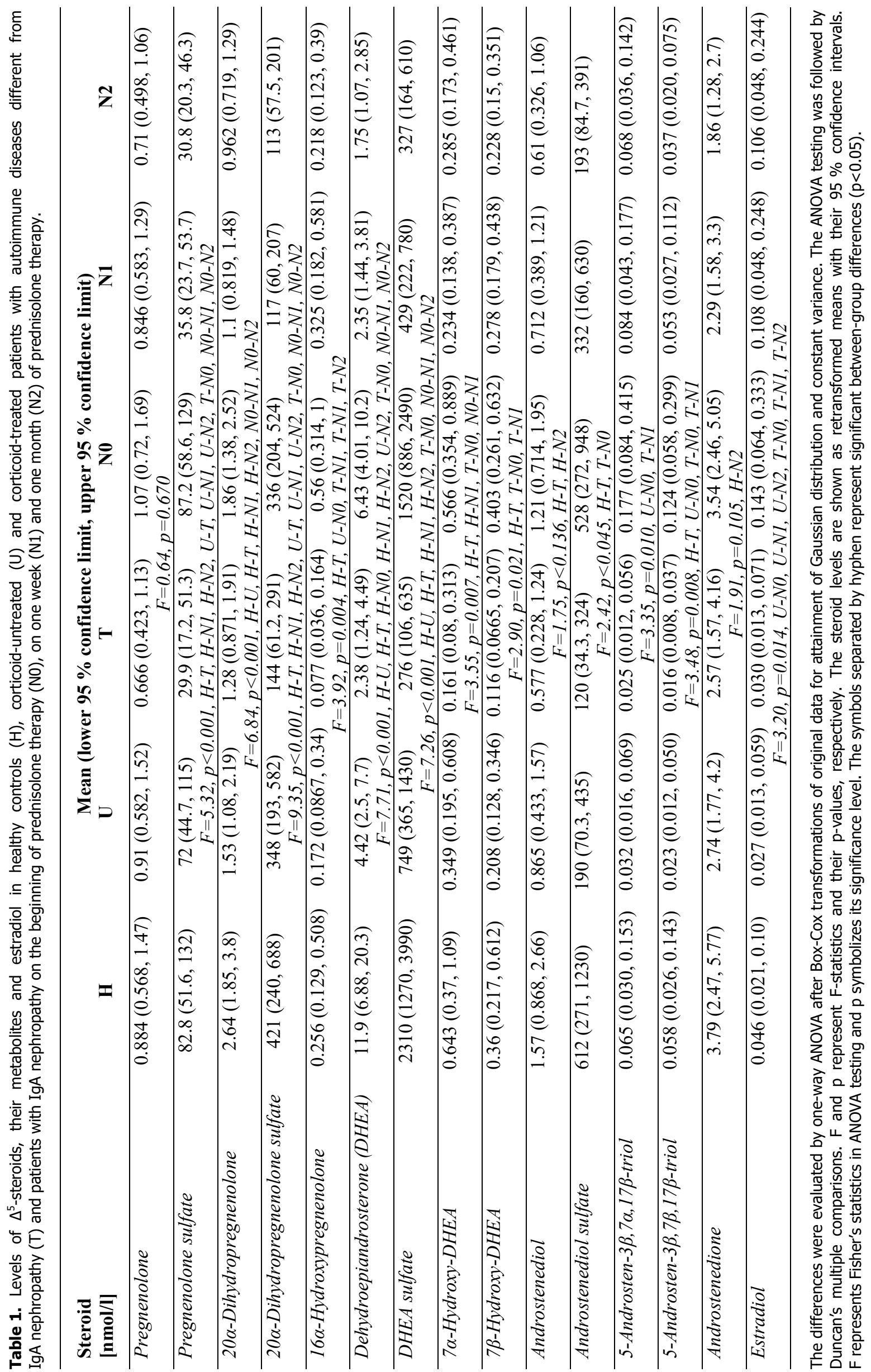




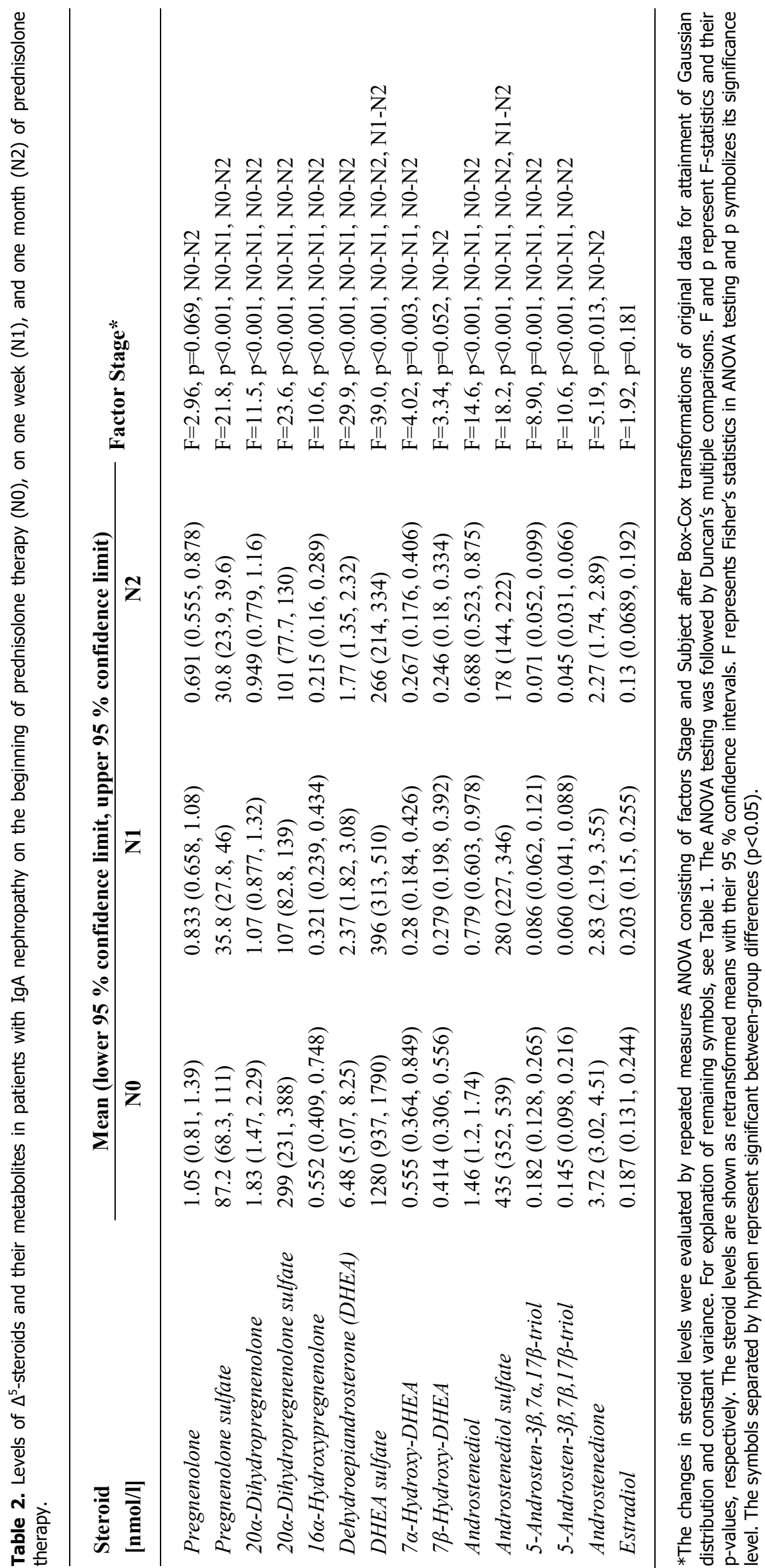



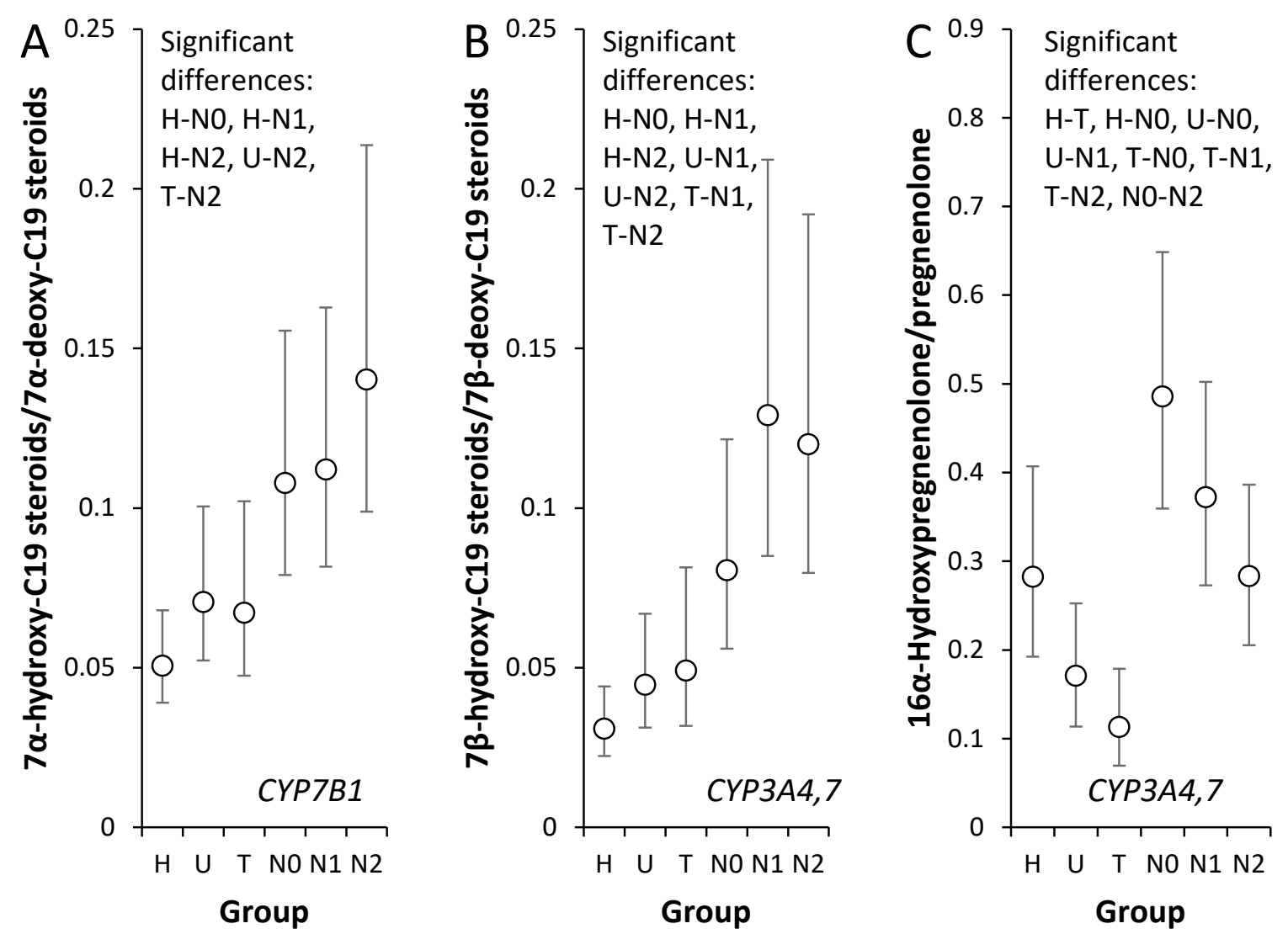

Fig. 2. Product to precursor ratios (PPRs) in groups of healthy controls $(H)$, glucocorticoid-untreated patients with autoimmune diseases (AD) different from IgA nephropathy (IgAN) (U), GC-treated patients with non-IgAN AD (T) and in IgAN patients on the beginning of prednisolone treatment (N0), after one week (N1) and after one month (N2) of the therapy. The text in italics illustrates the key enzymes, which may be reflected by the PPRs. For other drawings and symbols, see Figure 1. Panel A shows the PPRs reflecting a conversion of DHEA and androstenediol to their immunomodulatory 7a-hydroxy-metabolites. Panel $\mathbf{B}$ illustrates the PPRs reflecting a conversion of DHEA and androstenediol to their immunomodulatory $7 \beta$-hydroxy-metabolites. Panel $\mathbf{C}$ illustrates the PPRs reflecting a conversion of pregnenolone to 16a-hydroxypregnenolone.

and statistics for repeated measures ANOVA for the androstenedione/DHEA ratio were $\mathrm{F}=7.23, \mathrm{p}=0.003$ : $\mathrm{N} 0=0.561 \quad(0.422,0.738), \mathrm{N} 1=0.983 \quad(0.755,1.27)$, $\mathrm{N} 2=1.07 \quad(0.824,1.38), \quad \mathrm{N} 0-\mathrm{N} 1, \quad \mathrm{~N} 0-\mathrm{N} 2$. For the androstenedione/DHEAS ratio they were $\mathrm{F}=17.61$, $\mathrm{p}<0.001: \quad \mathrm{N} 0=0.0028 \quad(0.0021, \quad 0.0037), \quad \mathrm{N} 1=0.0066$ $(0.0052,0.0081), \mathrm{N} 2=0.0067(0.0054,0.0081), \mathrm{N} 0-\mathrm{N} 1$, N0-N2. The values in the H-groups were lower in comparison with the other groups for the androstenedione/DHEA ratio and similar results were found for the androstenedione/DHEAS ratio except for insignificant difference between the $\mathrm{H}$ and $\mathrm{N} 0$-groups.

Changing $7 \alpha$-, $7 \beta$ - and 16 $\alpha$-hydroxylation of $\Delta^{5}$-steroids in IgAN patients during the prednisolone treatment

Figure 2A shows the product to precursor ratio based on the levels of $7 \alpha$-hydroxy-DHEA (DHEA7 $\alpha$ ), 5 -androstene-3 $\beta, 7 \alpha, 17 \beta$-triol (AT7 $\alpha), \quad$ DHEA and androstenediol. This (DHEA $7 \alpha+\mathrm{AT} 7 \alpha) /(\mathrm{DHEA}+$ androstenediol) ratio exemplifies a conversion of DHEA and androstenediol to their $7 \alpha$-hydroxy-metabolites. This ratio was elevated in IgAN groups and showed an increase at the second stage of GC-therapy of IgAN patients $(\mathrm{F}=5.14, \mathrm{p}=0.014: \mathrm{N} 0=0.101 \quad(0.085$, $0.122), \mathrm{N} 1=0.094 \quad(0.079,0.114), \mathrm{N} 2=0.139 \quad(0.115$, $0.173)$, N0-N2, N1-N2).

Figure $2 \mathrm{~B}$ shows the product to precursor ratio based on the levels of $7 \beta$-hydroxy-DHEA (DHEA7 $\beta$ ), 5-androstene-3 $\beta, \quad 7 \beta, 17 \beta$-triol (AT7 $\beta), \quad$ DHEA and androstenediol. This (DHEA $7 \beta+$ AT7 $\beta) /($ DHEA+ androstenediol) ratio illustrating a conversion of DHEA and androstenediol to their immunomodulatory 7 $\beta$-hydroxy-metabolites exhibited a similar picture as in the case of $7 \alpha$-hydroxylation, except the transient increase during the GC-treatment $(\mathrm{F}=2.99, \mathrm{p}=0.068$ : $\mathrm{N} 0=0.079 \quad(0.061,0.105), \mathrm{N} 1=0.124 \quad(0.0914,0.176)$, $\mathrm{N} 2=0.117(0.087,0.164), \mathrm{N} 0-\mathrm{N} 1)$.

The 16 $\alpha$-hydroxypregnenolone/pregnenolone ratio reflecting the $16 \alpha$-hydroxylation of pregnenolone was also elevated in IgAN patients (Fig. 2C). However, 
this ratio decreased after $\mathrm{GC}$-application $(\mathrm{F}=7.82$, $\mathrm{p}=0.002: \quad \mathrm{N} 0=0.479 \quad(0.393,0.583), \mathrm{N} 1=0.366 \quad(0.3$, $0.447), \mathrm{N} 2=0.279(0.228,0.34), \mathrm{N} 0-\mathrm{N} 2)$.

\section{Discussion}

Reduced activity of adrenal zona reticularis (ZR) in IgAN patients

DHEA is an endogenous antiglucocorticoid serving as a precursor for the synthesis of 30-50\% of androgens in men and $100 \%$ of estrogens in postmenopausal women (Labrie et al. 1998). At physiological concentrations, this steroid stimulates the interleukin 2 (IL-2) secretion from $\mathrm{T}$ helper cells type 1 (Th1) cells but suppresses tumor necrosis factor $\alpha$ $(\mathrm{TNF} \alpha)$ and interleukin $\beta$ (IL1 $\beta$ ) production and activation of nuclear transcription factor $\kappa \mathrm{B}(\mathrm{NF}-\kappa \mathrm{B})$ pathway. DHEA mediates a cytotoxicity induced by $\mathrm{T}$ lymphocytes and enhances the natural killer (NK) cell cytotoxicity by stimulation of insulin-like growth factor 1 (IGF-1) production in NK cells. Furthermore, DHEA suppresses type $111 \beta$-hydroxysteroid dehydrogenase (HSD11B1) mRNA in adipose tissue and promotes the mRNA expression of type $211 \beta$-hydroxysteroid dehydrogenase (HSD11B2) in renal cells. HSD11B1 metabolite androstenediol, but not the DHEA, protects from viral-induced mortality (Loria 2002). In DHEA, DHEAS, androstenediol and DHEA/pregnenolone ratio, the between-group differences in adrenal androgens showed higher levels in the H-group in comparison with the N0-group, which indicates primarily reduced activity of the adrenal zona reticularis (ZR) in IgAN patients.

Glucocorticoid therapy additionally suppresses adrenal steroidogenesis in IgAN patients including the production of androgens and their immunoprotective 7- and 16 $\alpha$ oxygenated metabolites

The suppression of the hormonal production in zona fasciculata $(\mathrm{ZF})$ by prednisolone therapy was more prominent than the one in $\mathrm{ZR}$ as the DHEA/pregnenolone and DHEAS/pregnenolone ratios descended during the prednisolone treatment of IgAN patients. Endogenous GCs but not their synthetic analogues rapidly and dosedependently stimulated DHEA secretion. Cortisol had no influence on steroid C17-hydroxylase-C17,20-lyase (CYP17A1) but suppressed the activity HSD3B2 activity (Topor et al. 2011). The lack of natural GCs in IgAN patients elevated HSD3B2 activity, which promoted the conversion of adrenal $\mathrm{C} 19-\Delta^{5}$-steroids to their $\Delta^{4}$-counterparts and consequently reduced the levels of substrates for the synthesis of immunoprotective C19- $\Delta^{5}-7 \alpha / \beta$ - and $16 \alpha$-hydroxy-steroids, the synthesis of which is catalyzed by cytochrome P450 7B1 (CYP7B1), HSD11B1, cytochrome P450 3A4 (CYP3A4) and cytochrome P4503A7 (CYP3A7). Significant or borderline decrease during the GC-treatment was obvious in all C19- $\Delta^{5}$-steroids.

Increased estradiol levels in IgAN patients irrespectively of GC-therapy and amplified conversion of DHEA to androstenedione in IgAN patients

Adrenal androgens may be peripherally converted to autoimmunity-inducing estradiol (Ahlem et al. 2011a, Ahlem et al. 2011b, Auci et al. 2009, Conrad et al. 2010, Hennebert et al. 2007, Le Mee et al. 2008, Loria 2002, Pettersson et al. 2010, Reading et al. 2012, Tang et al. 2006). However, in spite of reduced synthesis of $\mathrm{C} 19-\Delta^{5}$-steroids in IgAN patients we surprisingly found higher estradiol levels (independently of GC therapy) when compared with non-IgAN groups (Tables 1 and 2). The estrogen overproduction in IgAN patients may be associated with an amplified conversion of DHEA to androstenedione (catalyzed by HSD3B2) as was observed in these subjects because the androstenedione is a key estrogen precursor (Luu-The 2013). Androstenedione/DHEA and androstenedione/ DHEAS ratios mounted during the GC-therapy and were higher in the T-group when compared with the H-group. We also found a different androstenedione/DHEAS ratio in the U-group when compared with both the H-group (higher values) and the T-group (lower values). Therefore, higher estradiol levels in IgAN groups may be also associated with increased aromatase activity.

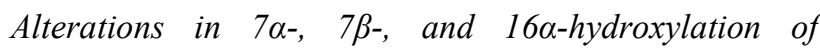 $\Delta^{5}$-steroids}

The mechanism explaining the immunomodulatory effects of $7 \alpha / \beta-\Delta^{5}$-steroids may be associated with a competition of 7-oxygenated androstanes for the active sites on the HSD11B1, which catalyzes the conversion of inactive 11-oxo-glucocorticoids to their immunosuppressive 11ß-hydroxy-counterparts (Hennebert et al. 2007, Le Mee et al. 2008).

Whereas estradiol induces autoimmunity via estrogen receptors, another mechanism is linked to the catabolism of C19 estrogen precursors such as DHEA, androstenediol, and $5 \alpha$-androstane- $3 \beta, 17 \beta$-diol (that are 
also estrogenic) to their 7-oxygenated and $16 \alpha$-hydroxylated catabolites, which cannot be further converted to bioactive estrogens (Pettersson et al. 2010). Androstenediol, even at low concentrations is active on both types of estrogen receptors. The AT7 $\beta$, which may be either formed by interconversion from the AT7 $\alpha$ or directly from androstenediol by the catalytic action of CYP3A4 and CYP3A7, is immunoprotective in spite of its low concentration and high clearance (Ahlem et al. $2011 b$ ). The synthetic antiinflammatory derivatives of AT7 $\beta$ suppress the production of $\mathrm{C}$-reactive protein interleukin 17 (IL-17), TNF $\alpha$, interleukin 6 (IL-6) signaling and expression of mRNAs for IL- 6 and matrix metalloproteinase in inflamed tissue but intensely stimulate the splenic regulatory $\mathrm{T}$ cells and suppress pro-inflammatory cytokines in the lungs (Reading et al. 2012). Estradiol may stimulate the catalytic CYP7B1 activity, mRNA, and human CYP7B1 reporter gene in human embryonic kidney cells HEK293 and may control the DHEA, estradiol, and androstenediol levels in human tissues (Tang et al. 2006). We have demonstrated that DHEA7 $\beta$, but not DHEA and DHEA7 $\alpha$ reduces the immunosuppressive effect of GCs on the formation of plaques in murine spleen lymphocytes (Sterzl et al. 1999). Therefore, the elevated conversion of the C19- $\Delta^{5}$-steroids to their $7 \alpha$ - and $7 \beta$-hydroxy-metabolites (catalyzed by CYP7B1, CYP3A4, CY3A7 and HSD11B1) in IgAN patients may represent a counterregulatory mechanism compensating the lack of C19- $\Delta^{5}$ deoxysteroids by amplified synthesis of their more efficient 7-oxygenated (autoimmunity-suppressing) metabolites. The 16 $\alpha$-hydroxylation of pregnenolone (catalyzed by CYP3A4, CYP3A7, CYP7B1) is also higher in IgAN patients. The only difference is the suppression of 16a-hydroxypregnenolone/pregnenolone ratio by GCs.

Possibilities of therapeutic co-application of $\Delta^{5}$-steroids and glucocorticoids

The C19- $\Delta^{5}$-steroids mitigate the severity of ADs (Bottasso et al. 2007, Du et al. 2001, Choi et al. 2008, Rontzsch et al. 2004, Sudo et al. 2001, Tan et al. 2009) but ADs may weaken the production of adrenal C19- $\Delta^{5}$-steroids (Bottasso et al. 2007, Kasperska-Zajac et al. 2008). DHEA controls the Th1/Th2 balance and either shifts it towards the Th1 component or attenuates the production of both components (Choi et al. 2008, Romagnani et al. 1998). The C19- $\Delta^{5}$-steroids also suppress cell-mediated immunity and formation of autoantibodies (Choi et al. 2008, Pratschke et al. 2014, Rontzsch et al. 2004, Sudo et al. 2001, Tan et al. 2009). Hence, the co-application of immunosuppressive corticoids with immunoprotective $\Delta^{5}$-steroids inducing restoration of the Th1-dominated cytokine profile (Hernandez-Pando et al. 1998b) may be favorable for the treatment of ADs. The GC-treatment alone exhibits more than $55 \%$ risk for adverse events (Lv et al. 2012) and the therapy exclusively with $\Delta^{5}$-steroids may be unsafe as well (Hernandez-Pando et al. 1998b). The therapeutic efficiency of androstenediol is higher in comparison with DHEA and the application of adrenal androgens is optimal in an early phase of Th1-mediated response and before the switch to the Th2-mediated stage (HernandezPando et al. 1998a).

\section{Conclusions}

The lack of adrenal androgens in IgAN patients might be a consequence of the disease linked to a lower activity of ZR. In addition, there is a further suppression of their synthesis by the GCs. Taking into account the effects of the adrenal androgens, their $7 \alpha, 7 \beta$, and $16 \alpha$-hydroxy-metabolites or their stable synthetic derivatives on the early stages of antibody-mediated ADs, the therapeutic co-application of the mentioned substances could be beneficial.

The finding of higher estradiol levels in IgAN patients is important as estradiol stimulates autoimmunity. Therefore, the increased conversion of C19- $\Delta^{5}$-steroids to their more efficient 7-oxygenated catabolites may be a protective mechanism against the excessive estradiol synthesis.

\section{Conflict of Interest}

There is no conflict of interest.

\section{Acknowledgements}

Supported by the grants MEYS CR (OP RDE, Excellent research - ENDO.CZ), OPPK CZ.2.16/3.1.00/21518 "Equipment for metabolomics research", and $\mathrm{MH} \mathrm{CZ} \mathrm{-}$ DRO (Institute of Endocrinology - EÚ, 00023761). 


\section{References}

AHLEM CN, AUCI DL, NICOLETTI F, PIETERS R, KENNEDY MR, PAGE TM, READING CL, ENIOUTINA EY, FRINCKE JM: Pharmacology and immune modulating properties of 5-androstene-3beta,7beta,17beta-triol, a DHEA metabolite in the human metabolome. J Steroid Biochem Mol Biol 126: 87-94, $2011 \mathrm{a}$.

AHLEM CN, PAGE TM, AUCI DL, KENNEDY MR, MANGANO K, NICOLETTI F, GE Y, HUANG Y, WHITE SK, VILLEGAS S, CONRAD D, WANG A, READING CL, FRINCKE JM: Novel components of the human metabolome: the identification, characterization and anti-inflammatory activity of two 5-androstene tetrols. Steroids 76: 145-155, $2011 \mathrm{~b}$.

AUCI DL, READING CL, FRINCKE JM: 7-Hydroxy androstene steroids and a novel synthetic analogue with reduced side effects as a potential agent to treat autoimmune diseases. Autoimmun Rev 8: 369-372, 2009.

BOTTASSO O, BAY ML, BESEDOVSKY H, DEL REY A: The immuno-endocrine component in the pathogenesis of tuberculosis. Scand J Immunol 66: 166-175, 2007.

CHOI IS, CUI Y, KOH YA, LEE HC, CHO YB, WON YH: Effects of dehydroepiandrosterone on Th2 cytokine production in peripheral blood mononuclear cells from asthmatics. Korean J Intern Med 23: 176-181, 2008.

CONRAD D, WANG A, PIETERS R, NICOLETTI F, MANGANO K, VAN HEECKEREN AM, WHITE SK, FRINCKE JM, READING CL, STICKNEY D, AUCI DL: HE3286, an oral synthetic steroid, treats lung inflammation in mice without immune suppression. J Inflamm (Lond) 7: 52, 2010.

DU C, KHALIL MW, SRIRAM S: Administration of dehydroepiandrosterone suppresses experimental allergic encephalomyelitis in SJL/J mice. J Immunol 167: 7094-7101, 2001.

DUNCAN DB: Multiple range and multiple F tests. Biometrics 11: 1-42, 1955.

HENNEBERT O, CHALBOT S, ALRAN S, MORFIN R: Dehydroepiandrosterone 7alpha-hydroxylation in human tissues: possible interference with type 111 beta-hydroxysteroid dehydrogenase-mediated processes. J Steroid Biochem Mol Biol 104: 326-333, 2007.

HERNANDEZ-PANDO R, DE LA LUZ STREBER M, OROZCO H, ARRIAGA K, PAVON L, AL-NAKHLI SA, ROOK GA: The effects of androstenediol and dehydroepiandrosterone on the course and cytokine profile of tuberculosis in BALB/c mice. Immunology 95: 234-241, 1998a.

HERNANDEZ-PANDO R, DE LA LUZ STREBER M, OROZCO H, ARRIAGA K, PAVON L, MARTI O, LIGHTMAN SL, ROOK GA: Emergent immunoregulatory properties of combined glucocorticoid and antiglucocorticoid steroids in a model of tuberculosis. QJM 91: 755-766, $1998 \mathrm{~b}$.

HILL M, PARIZEK A, KANCHEVA R, DUSKOVA M, VELIKOVA M, KRIZ L, KLIMKOVA M, PASKOVA A, ZIZKA Z, MATUCHA P, MELOUN M, STARKA L: Steroid metabolome in plasma from the umbilical artery, umbilical vein, maternal cubital vein and in amniotic fluid in normal and preterm labor. $J$ Steroid Biochem Mol Biol 121: 594-610, 2010.

KASPERSKA-ZAJAC A, BRZOZA Z, ROGALA B: Dehydroepiandrosterone and dehydroepiandrosterone sulphate in atopic allergy and chronic urticaria. Inflammation 31: 141-145, 2008.

LABRIE F, BELANGER A, LUU-THE V, LABRIE C, SIMARD J, CUSAN L, GOMEZ JL, CANDAS B: DHEA and the intracrine formation of androgens and estrogens in peripheral target tissues: its role during aging. Steroids 63: 322-328, 1998.

LAI KN, TANG SC, SCHENA FP, NOVAK J, TOMINO Y, FOGO AB, GLASSOCK RJ: IgA nephropathy. Nat Rev Dis Primers 2: 16001, 2016.

LE MEE S, HENNEBERT O, FERREC C, WULFERT E, MORFIN R: 7beta-hydroxy-epiandrosterone-mediated regulation of the prostaglandin synthesis pathway in human peripheral blood monocytes. Steroids 73: 1148-1159, 2008.

LORIA RM: Immune up-regulation and tumor apoptosis by androstene steroids. Steroids 67: 953-966, 2002.

LUU-THE V: Assessment of steroidogenesis and steroidogenic enzyme functions. J Steroid Biochem Mol Biol 137: 176-182, 2013.

LV J, XU D, PERKOVIC V, MA X, JOHNSON DW, WOODWARD M, LEVIN A, ZHANG H, WANG H: Corticosteroid therapy in IgA nephropathy. J Am Soc Nephrol 23: 1108-1116, 2012. 
MASTORAKOS G, KAROUTSOU EI, MIZAMTSIDI M: Corticotropin releasing hormone and the immune/inflammatory response. Eur J Endocrinol 155: S77-S84, 2006.

MATOUSOVIC K, MESTECKY J, VONDRAK K, DUSEK J, CHVATALOVA E, HACEK J, HORYNOVA M, KASPEROVA A, ROSSMANN P, STERZL I, RASKA M: IgA Nephropathy. Facts, uncertainties, potential causal therapy approaches (in Czech). Cas Lek Cesk 154: 168-173, 2015.

MESTECKY J, RASKA M, JULIAN BA, GHARAVI AG, RENFROW MB, MOLDOVEANU Z, NOVAK L, MATOUSOVIC K, NOVAK J: IgA nephropathy: molecular mechanisms of the disease. Annu Rev Pathol 8: 217-240, 2013.

PETTERSSON H, LUNDQVIST J, NORLIN M: Effects of CYP7B1-mediated catalysis on estrogen receptor activation. Biochim Biophys Acta 1801: 1090-1097, 2010.

PRATSCHKE S, VON DOSSOW-HANFSTINGL V, DIETZ J, SCHNEIDER CP, TUFMAN A, ALBERTSMEIER M, WINTER H, ANGELE MK: Dehydroepiandrosterone modulates T-cell response after major abdominal surgery. J Surg Res 189: 117-125, 2014.

RAUEN T, EITNER F, FITZNER C, SOMMERER C, ZEIER M, OTTE B, PANZER U, PETERS H, BENCK U, MERTENS PR, KUHLMANN U, WITZKE O, GROSS O, VIELHAUER V, MANN JF, HILGERS RD, FLOEGE J: Intensive supportive care plus immunosuppression in IgA nephropathy. $N$ Engl J Med 373: 2225-2236, 2015.

READING CL, FRINCKE JM, WHITE SK: Molecular targets for 17alpha-ethynyl-5-androstene-3beta,7beta,17betatriol, an anti-inflammatory agent derived from the human metabolome. PLoS One 7: e32147, 2012.

RENGARAJAN S, BALASUBRAMANIAN K: Corticosterone induces steroidogenic lesion in cultured adult rat Leydig cells by reducing the expression of star protein and steroidogenic enzymes. $J$ Cell Biochem 103: 1472-1487, 2008.

ROMAGNANI S, KAPSENBERG M, RADBRUCH A, ADORINI L: Th1 and Th2 cells. Res Immunol 149: 871-873, 1998.

RONTZSCH A, THOSS K, PETROW PK, HENZGEN S, BRAUER R: Amelioration of murine antigen-induced arthritis by dehydroepiandrosterone (DHEA). Inflamm Res 53: 189-198, 2004.

STERZL I, HAMPL R, STERZL J, VOTRUBA J, STARKA L: 7Beta-OH-DHEA counteracts dexamethasone induced suppression of primary immune response in murine spleenocytes. J Steroid Biochem Mol Biol 71: 133-137, 1999.

SUDO N, YU XN, KUBO C: Dehydroepiandrosterone attenuates the spontaneous elevation of serum IgE level in NC/Nga mice. Immunol Lett 79: 177-179, 2001.

TAN XD, DOU YC, SHI CW, DUAN RS, SUN RP: Administration of dehydroepiandrosterone ameliorates experimental autoimmune neuritis in Lewis rats. J Neuroimmunol 207: 39-44, 2009.

TANG W, EGGERTSEN G, CHIANG JY, NORLIN M: Estrogen-mediated regulation of CYP7B1: a possible role for controlling DHEA levels in human tissues. J Steroid Biochem Mol Biol 100: 42-51, 2006.

TESAR V, TROYANOV S, BELLUR S, VERHAVE JC, COOK HT, FEEHALLY J, ROBERTS IS, CATTRAN D, COPPO R: Corticosteroids in IgA nephropathy: a retrospective analysis from the VALIGA study. J Am Soc Nephrol 26: 2248-2258, 2015.

TOPOR LS, ASAI M, DUNN J, MAJZOUB JA: Cortisol stimulates secretion of dehydroepiandrosterone in human adrenocortical cells through inhibition of 3betaHSD2. J Clin Endocrinol Metab 96: E31-E39, 2011. 